\title{
Between 'Devil' and Detoumement Embodied Ac ts as Methods of Critical Inquiry in Educational Spaces.
}

\section{Robert Wilson Sweeny1}

\begin{abstract}
This paper explores the relationship between surveillance technologies and power as exercised in educational spaces. The theories based in the panoptic gaze as theorized by Michel Foucault provide educators with the opportunity to analyze positions of power in school settings. The critical actions of the Surveillance Camera Players represent examples of active embodiment that might inform a form of pedagogy that investigates panopticism within educational spaces.
\end{abstract}

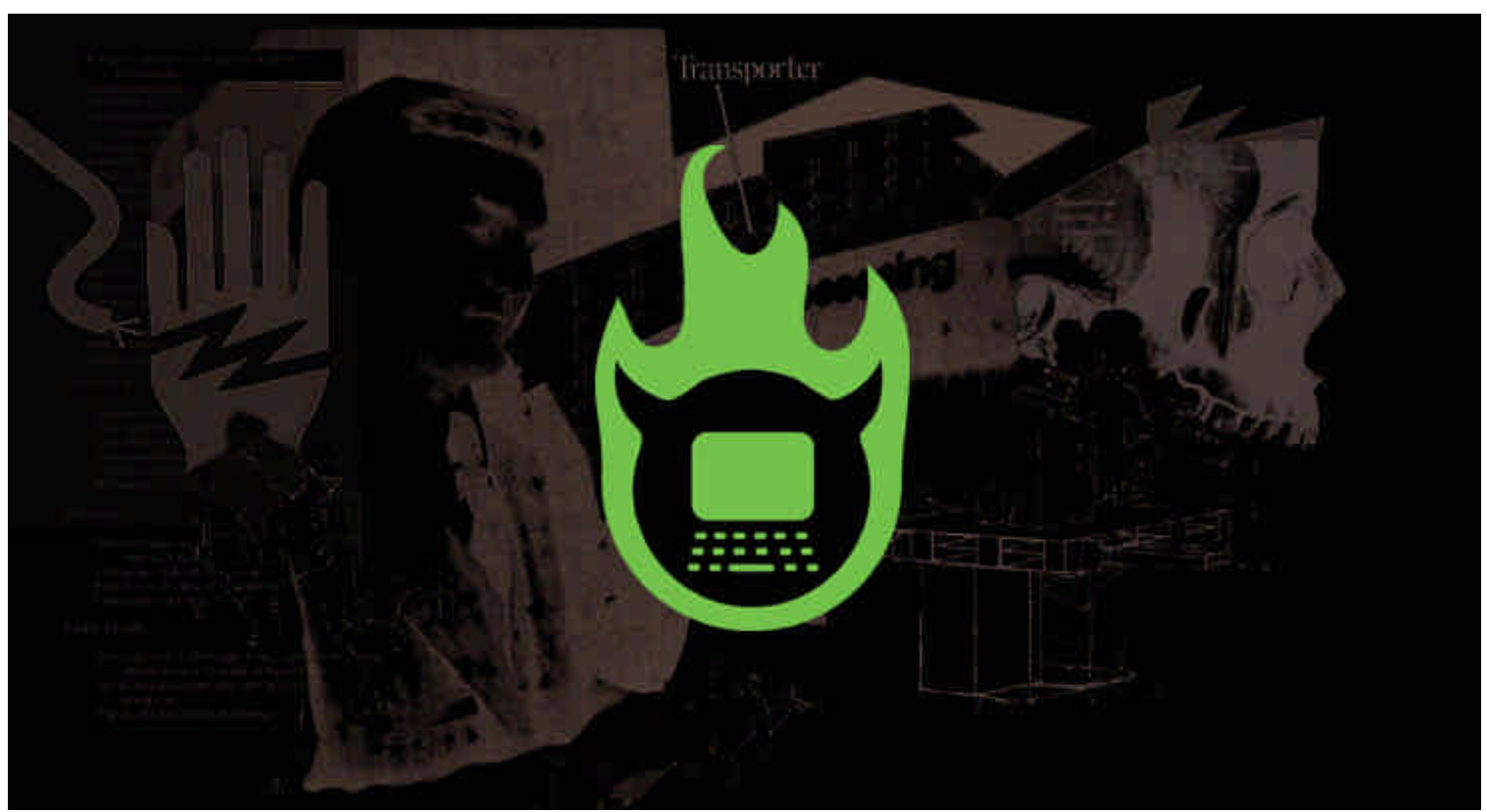

Image 1: Technology is the Devil Source: http://www.angelfire.com/electronic 2/tec hnologyisthed evil

${ }^{1}$ The Pennsylvania State University, State College, Pennsylvania, US. mailto:Rws173@psu.edu 


\section{Introduction}

I walked out of the classroom as my students were walking in. Many of us crossed paths at the entranceway, exchanging confused looks for a nervous glance, a semi-confident smile. I was moving across campus as they settled into their seats, logged on to the network, checked email or chatted using IM. They activated their databodies as I initiated bodily action, firing neurons that synchronize bones and muscles, limbs and torso, moving at a steady pace.

The students in 'Art 100: Concepts and Creations in the Visual Arts' insinuated themselves into machinic networks as I negotiated social pathways, aided by a fellow graduate instructor. They entered passwords, resized windows, responded to electronic prompts. I held the door for the person following me out of the building, I looked both ways before crossing the street, I deflected the glances of the people who stared for a millisecond too long, at my quick pace, and the sign that I held at chest level, its fragmentary proclamation: "is the devil."

I was somewhat preoccupied, thinking about how I felt one year earlier, when I had constructed and presented a similar performance meant to interact with and therefore address the possibilities for critiquing surveillance technologies. In both actions I had left a classroom entirely constructed around visible digital technologies, jammed full of laptop computers, printers, and projection equipment, and moved towards a public place, on the campus of a major public university, which had recently become home to technologies intent on remaining invisible.

All of the preparation that I had put into the class - developing the website, uploading it to a cranky server, playing with different forms of advertising which included sending an announcement to Rhizome.org, constructing the 15-foot long sign that morning - had built up to that moment, a moment so simple that it did not provide any indication of the planning that had preceded it, or of the events which might occur as a result. My fellow instructor and I stood at the edge of the second-story balcony which overlooked the main walkway, unfolded our sign, and held it for two minutes as we faced the surveillance camera (Image 1).

The class was a bit restless when we returned. We heard a few scattered claps. Someone said something about '. . . devilish bastards.' I had anticipated seeing the image of the sign projected for the class to see. Confronted with a blank screen, we shifted our initial plan, which was to compare our presence in the classroom and our image on the screen, to discuss the relationship between the website and the performance.

After a few minutes of clicking computer keys, one student - Jim - proclaimed that there was an ironic aspect to the website. When asked to explain his answer, he gave an example of a tank which, if hit by an enemy missile, would explode outwards instead of inwards, potentially destroying the enemy in the process. "Irony is a kick in the ass," he went on to say.

The class discussed and built upon the idea that irony is self-reflexive, that something is ironic only when you judge the statement, or the action, by what has been said or done by the subject previously. A website that proclaims 'technology is the devil.' Is this an example of simple circularity? A double negative? Medium the message, even when the message is anti-medium? 
Every village, even McLuhan's global village, needs its idiot.

Students then responded to specific aspects of the website, altogether dismissing the performance that had introduced the class. Many responded to the robot-like image of the computer user included on the site (Image 2). One student insisted that the ergonomic diagram that depicting the user sitting an optimal distance from the screen would not be relevant in the future, when computer screens would be projected, or worn. The students would not be in a fixed position, as they were that day in class. He was responding primarily to the text that accompanied the image of the computer user: "The user loses bits of identity as they interact with the machine..."

I then posed a few questions: How can participants in a visual art class form critical responses to digital technologies? Do we form such responses without acknowledging their presence? What are some possibilities for active embodied responses to networked technologies such as surveillance cameras? I then asked everyone to look around the room, comparing the way in which they were sitting to their computer to the diagram in the screen. The class was silent.

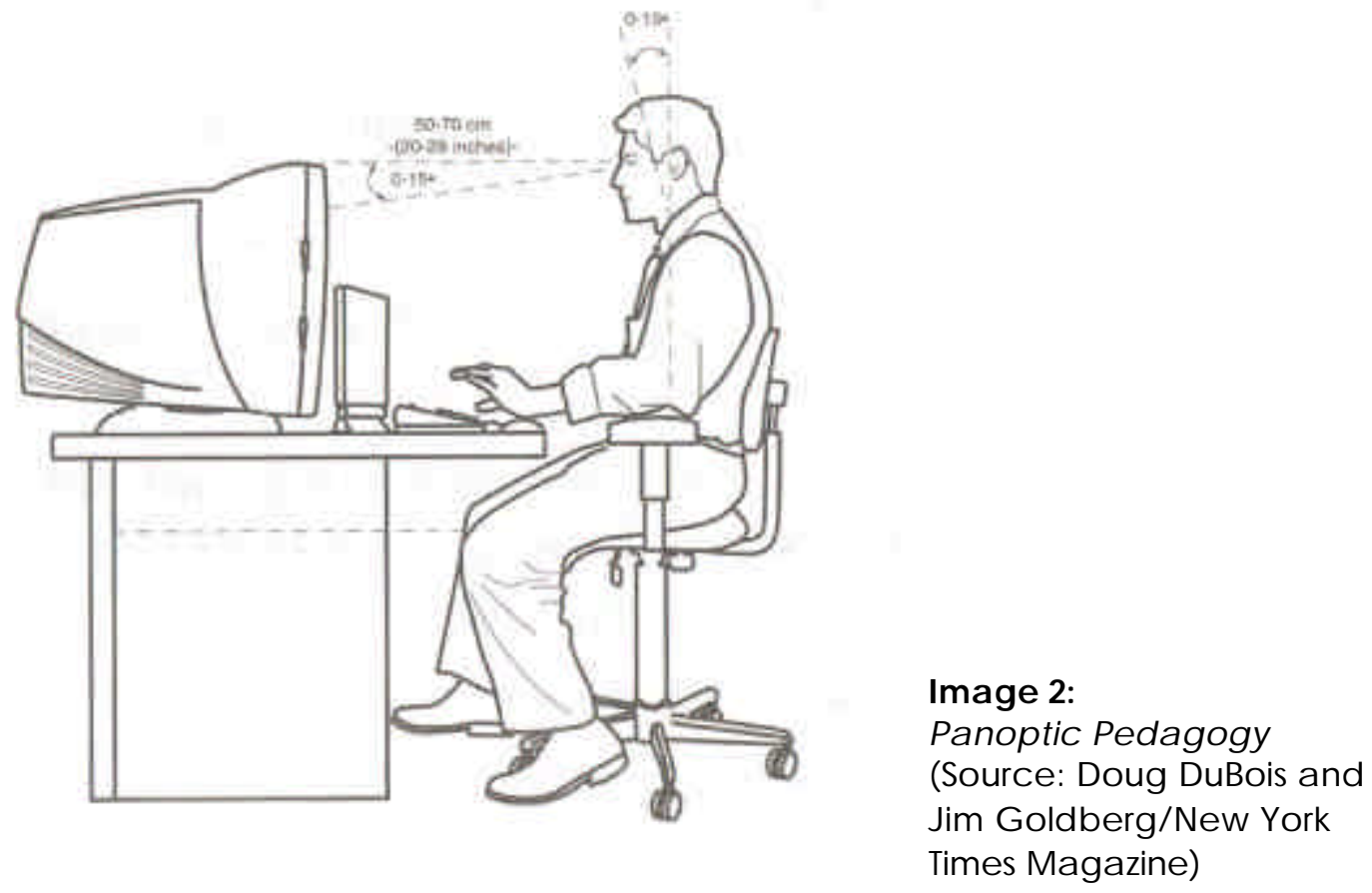

Classrooms rely upon elaborate networks of surveillance and control - both visible and hidden - in order to efficiently and subtly monitor student behavior. The recent installation of surveillance cameras in more than 500 classroom in Biloxi, Mississippi public schools stands as a blatant example of this impulse taken to an extreme (CNN.com, 8/13/2003). The increased appearance of surveillance technologies in a variety of social spaces creates situations that call for critical explorations. The series of actions that introduced this paper - referred heretofore as devill.o - represent an attempt to interrogate contemporary surveillance technologies as they

\footnotetext{
${ }^{2}$ Source: http://www.courses.psu.edu/art/art100 rws173
} 
relate to and operate within educational spaces. Educators who are confronted with increasingly sophisticated forms of technology may find possibilities for critique in practices related to notions of active embodiment; failure to address these issues could result in practices that multiply the oppressive potential of such technologies.

I have used embodied forms of critique in my practice as an art educator in order to address issues of power both in and outside of educational spaces. I am specifically interested in the critical potential for activities that utilize networked digital technologies such as the Internet. The multifaceted nature of the Internet has made it a space for contestation and collaboration, political action and oppression. The networked actions carried out by the Surveillance Camera Players address many of these issues, specifically related to individual rights and civil liberties. They do so through confrontation and subversion, embodying the technologies that they critique in ways relevant to educational spaces.

This discussion of the potential for the critique of surveillance technologies will begin with the social effects of surveillance identified in the theories related to the Panopticon as proposed by Michel Foucault (1975). Following this general discussion of panopticism as it relates to educational spaces, the approaches utilized by the Surveillance Camera Players will be analyzed. The pedagogical aspects of their practices will be discussed, specifically as they relate to the work of Situationist International, in the hopes that this relationship might shed light on possibilities for critical interventions in classrooms.

This paper will conclude with a discussion of the possibilities for embodied forms of critique in educational spaces, influenced by the writings of N. Katherine Hayles (1999). If carefully designed and applied, such critiques can allow for discussions of power and technology to operate in classrooms that are nodes within a multitude of intertwined networks - dense weaves of panoptic technologies potentially frayed through the friction of embodied actions.

\section{Panoptic pedagogy: Fouc ault and surveillance in educational spaces}

Michel Foucault discusses the extent to which western societies have integrated disciplinary technologies in Discipline and Punish: The Birth of the Prison (1975). He outlines a variety of social spaces that operate according to mechanisms of surveillance, including prisons, hospitals, factories and schools. While he emphasizes the development of various notions of discipline as related to prisons, specifically in France and the United States, he also makes frequent reference to the relationship between prison and school structures. He states: "A relation of surveillance, defined and regulated, is inscribed at the heart of the practice of teaching, not as an additional or adjacent part, but as a mechanism that is inherent to it and which increases its efficiency" (176)

Foucault bases much of this argument upon aspects of schooling that orders the behavior of individual students, such as regimented time frameworks and methods of observation including desks arranged in grids. In his discussion of social disciplinary structures he describes the move from corporal punishment to a more general method of discipline. In order to provide a diagram for this abstraction of social control, he refers to the structure known as the Panopticon, the 
prison design developed by Jeremy Bentham in 18th century England. Foucault proposes that the panoptic nature of education is inherent to its functioning within a modern, ordered society. This order is reinforced through subtle, pervasive individualized actions.

If we accept the proposition that educational spaces are inherently panoptic, we must ask the following: can individuals resist this ordering, or are actions that are consistently monitored and controlled always a product of educational spaces? In his development of the Panopticon as emblematic of modern surveillance, Foucault proposes that this ordering becomes a part of the actions of the individual. In schools, prisons, hospitals, the individuals perform a self-monitoring, inscribing the disciplinary restrictions upon their bodies, while the actual technologies disappear into the ideological frameworks of the various institutions.

Curriculum theorists Michael Apple and Nancy King (1990) describe a similar shift in forms of control in educational spaces. In their Marxist analysis of social control and schooling they refer to the notion of the 'hidden curriculum,' a phrase used variously in educational literature. Apple and King suggest that a general shift in educational ideologies has taken place in the 20th century, from administering and reinforcing social control - an acknowledged aspect of early forms of public education - to approaches that reflect broad humanistic values. The elements of control, still operational in educational spaces, are thereby subsumed beneath the rhetoric of humanism: individualism, self-expression. The 'hidden curriculum' therefore represents the oppressive potential of public schools in general.

The panoptic tendency towards lightness (Deleuze, 1990) and individual embodiment must be compared to this notion of the 'hidden curriculum,' as they may describe similar power relationships in educational spaces. While Foucault (1975) describes conditions during the 18th and 19th centuries in France (and the United States, to a lesser degree), Apple and King (1990) focus upon more recent educational situations, primarily within the 20th century United States. The 'hidden curriculum' typically operates beneath the intentions of those in positions of power within schools - teachers, principals, and curriculum specialists - while panoptic forms of monitoring and control can be actively applied by anyone within networks of surveillance. The installation of surveillance cameras in Biloxi, Mississippi schools, mentioned earlier, only makes visible the multiform networks of surveillance already in operation in most classrooms. Similarly, acknowledging the possibility of a 'hidden curriculum' within educational spaces does very little to uncover the agenda of those in power. It is the responsibility of those in power to respond to the challenges to authority that take place every day in classrooms. These acts, formed primarily by students, serve as openings within the networks of power and surveillance. These openings might allow for a discussion of that which is hidden, an uncovering of the unspoken examples of critique in educational spaces.

It is important to acknowledge the multiple forms of surveillance that occur in many classrooms. Although the teacher might assume the position of power - mimicking the centralized tower in the Panopticon - there are also the varied, often covert acts performed by students that combine to form a "micro-physics of power" (Foucault, 1975, p. 139). In the panoptic space of the classroom, all have the potential to see and be seen. A more relevant question is thus: How are the responses to these networks of surveillance registered? If the individuals in the classroom 
space embody various responses to panoptic forms of power, what do these responses look like?

In devil1.0 I directly confronted the surveillance camera in the union building. In this space the invisible technologies of panoptic power are made visible - in fact advertised, as we will soon see. Was this an example of resistance, or did it reinforce the ordering that accompanies the technology? It is quite possible that it represents both possibilities; I resist the ordering of the panoptic gaze, only to reinforce it with my return to the classroom.

In order to pursue these questions, and to inquire as to the possibilities for critiquing the panoptic gaze within general educational spaces, I will now turn to a group that confronts surveillance technologies through minimal public actions: The Surveillance Camera Players (SCP). The notion of active embodiment as critique will be developed through an analysis of the tactics of the SCP as related to the methods of social critique of the Situationist International, and theories of embodiment proposed by N. Katherine Hayles (1999).

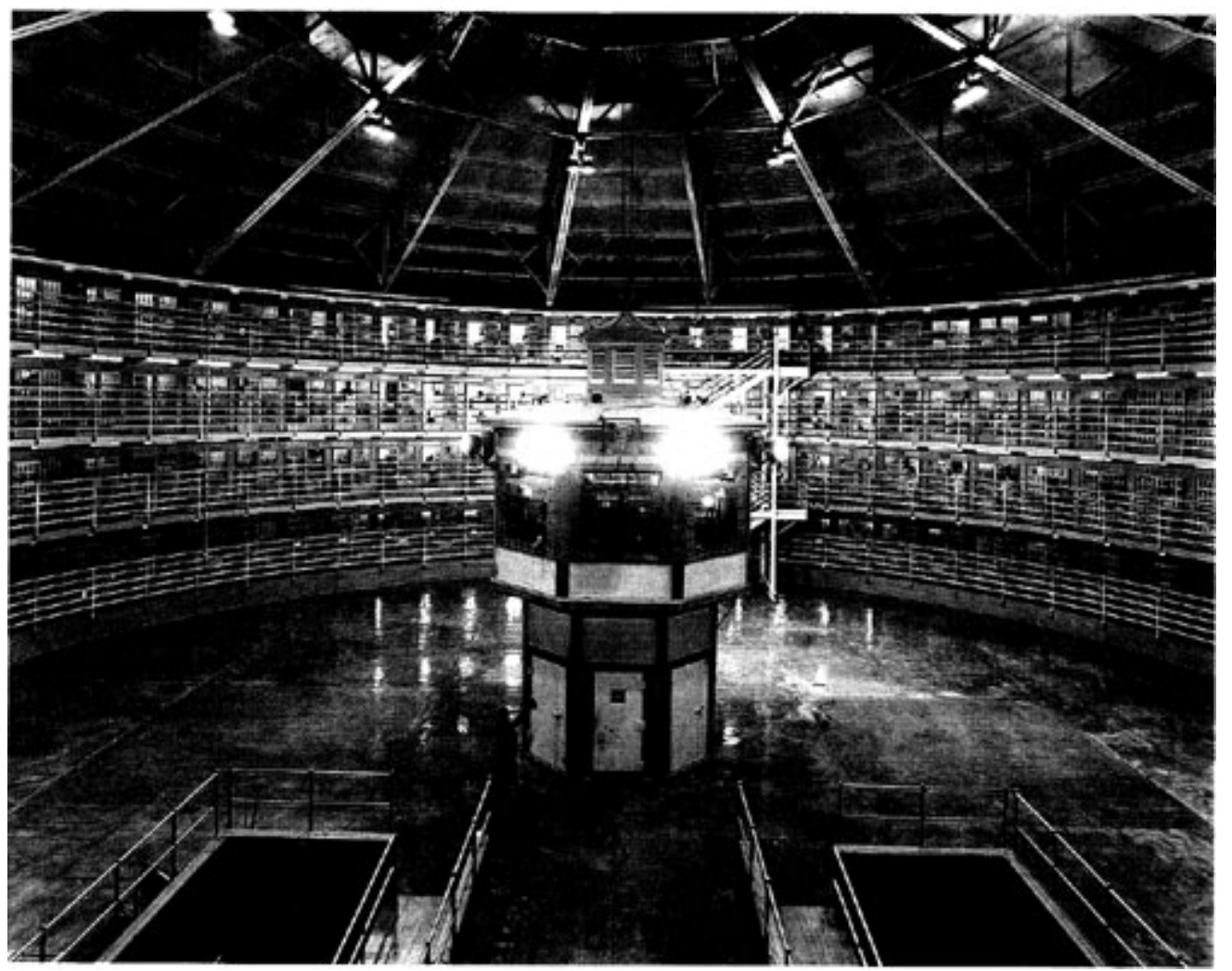

Image 3: Panoptic on

\section{'We feed the spectacle poison, disguised as bird seed'}

The SCP is a group who use simple means in order to confront public surveillance technologies. They are a loosely defined collective made up of active members located around the world who utilize existing surveillance camera networks in order to present short skits and plays, which often 
have direct references to the politics of surveillance, civil liberties, and constitutional rights in the United States. The performances are often spontaneous, and are rarely seen by a public beyond those in the vicinity of the camera, unless security videos are obtained, or the cameras happen to be available for viewing on the web.

Although most of the activities of the SCP do not directly address surveillance as it relates to the Internet, as in the case of devil1.0, events such as 'World Surveillance Day' utilize the global network in order to organize and synchronize performances related to surveillance technology. As stated by SCP founder Bill Brown:

We use the Internet as much as we can to maximize our effectiveness. Though the group would be far less well known without the Internet. But the "Surveillance Camera Players" could still exist and be effective even if the Internet were to crash en masse tomorrow. This is why our Web site is relatively rudimentary and toned down. It is simply a vehicle to deliver ideas over a very wide area. And it allows the "SCP" to do without a newsletter or book. . .

(Baumgaertel, 2001)

The Internet adds considerable range to the work of the SCP. Although they use their site primarily for the documentation of their performances and posting related writings, their ideas are disseminated on an unprecedented scale, allowing for like-minded individuals to participate, or organize similar activities. The Internet also extends the mechanics of surveillance, creating viewers for actions that would otherwise be relatively unacknowledged. The surveillance-based actions of the SCP become the object of surveillance, multiplying their actions.

The intricate forms of surveillance that take place on the Internet involve a number of participants, from high-level government officials to anonymous individuals. As Foucault (1975) proposes, the power of the Panopticon can be found specifically in its diffusion throughout all aspects of society; it is a mechanism that allows for multiple entry points. The intricate layers of surveillance that are manifested through the decentralized structure of the Internet are directly addressed through the devill.0 action.

The online availability of the images from the 'HUBcam' makes all viewers into not only voyeurs, but into potential legislators of behavior. The pseudo-interactivity promoted on the website plays with this idea. The personalization of the space, represented by the ability to submit suggestions for signs to be displayed in the union building - in 'real-time' - is subverted by the doctored images, depicting prefab placards that relate to my interests, not those of the web 'visitor'. (Image 4) This aspect of the webpage was designed to address he questions of interactivity that accompany the ability to view the HUBcam images online. The surveilled space seems to call out for actions that engage with the networked camera. 


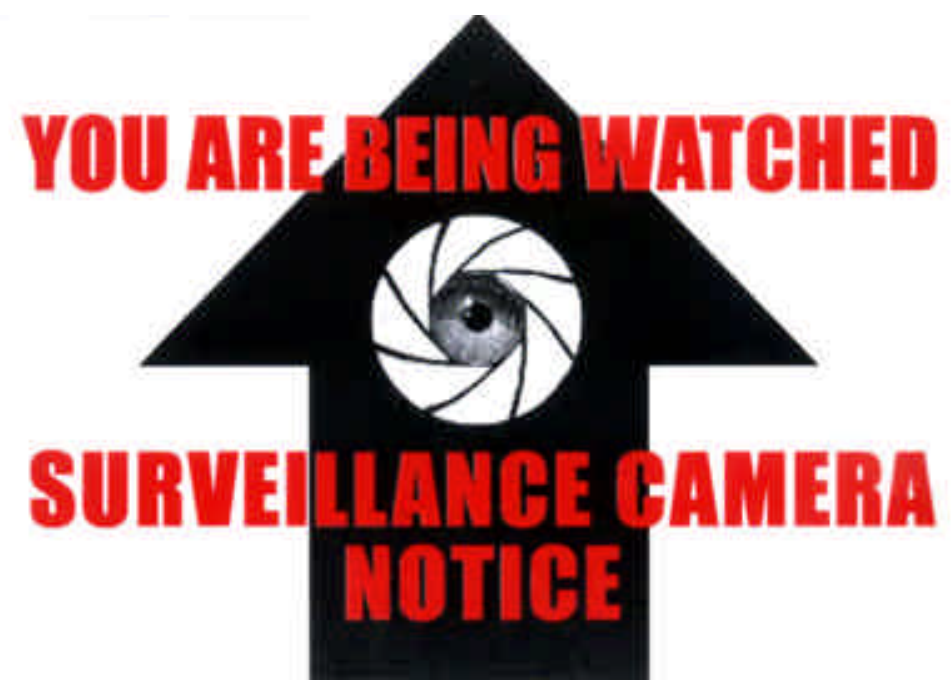

Image 4:

Surveillance Camera Notice

These examples raise the following question: is any act that returns the gaze of the surveillance camera to be considered critical? I would argue that to a certain extent it is; however, devill.0 specifically addresses the technology in question - "technology is the devil" - and is therefore a direct response to the camera itself, not just those viewing the 'real-time' images. In a similar manner, the skits and plays organized by the SCP often make direct reference to the oppressive potential of surveillance technologies: Orwell's 1984, for instance.

If the Internet represents a panoptic form of social control, are the actions of those who use it inscribed in a similar manner? The Panopticon derives its power through a centralized power structure, as we have discussed, whereas the Internet is decidedly decentralized (Barabasi, 2003). While both are diffused throughout society, the subject of the panoptic gaze is made passive through the inscriptive power of this gaze: "He is seen, but he does not see" (Foucault, 1975 , p. 200). In comparison, the Internet user has the potential for active engagement with the technology, the ability to see the actions of others and to be seen. As Rheingold (2002) points out, the decentralized nature of the Internet makes it a fluid, contested space, accessible by political activists and international terrorists alike.

The problematic nature of devill.0 rests in the active/passive dichotomy- I reinforce the notion of active embodiment while assuming that they embody a form of passive interaction. I struggled to compose a series of actions that would address these issues without reinforcing the very power that I was intent on critiquing. Had I asked the students to construct a response to the technology, to enter the gaze of the surveillance cameras, I would have forced my idea of active embodiment upon them. Instead I offer my own response, one that refers specifically to the technology in question. In this manner it is less problematic to have them respond to the idea of passiveness in the classroom, and to construct their own response, than it is to force action upon them.

The binary of active/passive interaction is disrupted through the performances of the SCP. The public space becomes a theater for engagement, allowing for the viewer to acknowledge their position within the space, and possibly participate. Blurring the lines between performer and 
audience, the SCP represent a form of engagement that investigates notions of spectacle.

Bill Brown acknowledges the influence of the group known as Situationist International (SI) upon his critical surveillance tactics. A brief study of the tactics of SI - specifically their notion of detournement - will provide a theoretical to better understand the critical nature of these actions, in regards to political activism and the possibility for a pedagogy that is critical of surveillance technologies.

\section{Stuationist tactics and surveillance}

SI was organized in 1957, from a few European avant-garde groups such as the Lettrists and CoBrA (Knabb 1981, ix). Much of their critique of capitalism and related social effects was based in the practice of detournement. An analysis of the act of detournement will provide a useful analytical tool with which to better understand the actions of the SCP, and my own as well.

Guy Debord, founding member of SI, described detournement as follows:

Detournement: Short for: detournement of preexisting aesthetic elements. The integration of present or past artistic production into a superior construction of a milieu. In this sense there can be no situationist painting or music, but only a situationist use of these means. In a more primitive sense, detournement within the old cultural spheres is a method of propaganda, a method which testifies to the wearing out and loss of importance of those spheres.

(Debord, in Knabb, 1958 (1981), p. 46)

The primary act for the situationist movement was detournement. In terms of the use of 'preexisting aesthetic elements,' detournement might be thought of as a form of appropriation. This appropriation would take into consideration the political nature of the action, in keeping with the revolutionary emphasis of the Situationists. This act allows for the subversion of the original use of the form of 'production' in order to enter it into new channels of use and critique, and eventual reappropriation. While initially negated, the cultural power of the 'detourned' object inevitably reappears, creating a "double meaning, from the enrichment of most of the terms by the coexistence within them of their old senses and their new, immediate senses" (Debord, in Knabb, 1958 (1981), p. 55).

The double meaning produced through detournement should be acknowledged as a form of critique, allowing for the existence of acts that analyze and confront cultural objects without drastically altering the physical aspects of the appropriated object. What is the effect of this double negation? Is it similar to the linguistic double-negative that creates a positive? Or, is this an act of deconstruction, resulting in the creation of a void from which nothing can be produced? The act of detournement raises certain fundamental questions when addressing the critical nature of activities organized by the SCP. Are the performances that 'detourn' the spectacle of the cameras examples of critique, or do their lo-tech actions merely reinforce the power of the 
cameras to place constraints on behavior?

These questions may be addressed by returning to the initial discussion relating to the use of the Internet by the SCP. The website should be seen as a crucial element in the activities of the SCP. It allows for their actions - and their accompanying ideology - to enter into the stream of information that makes up the Internet. In this manner its function is similar to that of the SI journal. Making the critique available to a larger audience, the publishing of both 'documents' allows for dissemination on a larger scale. This dissemination places the responsibilities inherent to surveillance on the Internet viewer $-\mathrm{s}$ /he chooses to perpetuate the surveilled gaze, looking at the image without question, or perform a detournement similar to that of the SCP.

Bill Brown makes specific reference to the possibilities for detournement as critique: "What we do is 'detourn' the spectacle of the cameras. We don't destroy them as militant anarchist would do. We don't write to our congressman as good leftist would do. We turn the cameras against their original purposes" (Brown, interview, 2001). These actions are meant to be seen, meant to confront the technology of surveillance as it is actively used in public spaces. In fact, the actions of the SCP create spectacle in areas where surveillance technologies rely upon discrete, individualized observations. Much of the transition from punishment to monitoring that Foucault (1975) describes is based in the shift in social forms of interaction: "Our society is not one of spectacle, but of surveillance" (217).

Although the Situationists advocated for the dismantling of the spectacle, they could not avoid the transmission of their ideas through their self-published journal. Both groups understood the potential for dialogue to offer critical reflection. Dialogue is created in social spaces and in the writings of the Situationists. In the case of the SCP it is created in the public space, dealing with interactions between performer and camera, performance and audience, spectacle and surveillance.

As I write about my actions in the art classroom, I inevitably enter into similar media networks. I see the necessity for involvement within these technological networks, if only to provoke dialogue that might lead to their limitation. My research in fact relies upon a generalized surveillance, viewing and documenting class activities so that they might inform future theories and practices. Just as the Situationist hoped to critique aspects of capitalistic societies through detournement, I hope to critique my own practice through similar means. devill.0 represents an attempt to create a double meaning within the classroom, critiquing my own power by standing alongside my own image, creating a website that questions the effects of the computer on individual users. As I begin to question the panoptic nature of my practice I enter the realm of irony. My actions become a kick in the ass. Or, more pointedly, me kicking my own ass.

The SCP has recently started to offer walking tours that highlight the existence of surveillance cameras. ${ }^{3}$ These tours - most of which occur in Manhattan - consist of small groups walking through typically crowded areas such as SOHO, led by Brown. Describing the various types of

\footnotetext{
${ }^{3}$ For a film of one of these tours, and another interview, see: Surveillance \& Society 1(3), available online at: http://www.surveillance-and-society.org/journalv1i3.htm
} 
surveillance cameras - first, second and third generation - and other technologies such as microwave transmitters, Brown's tours are a nuisance to those going about their daily activities. They are also quite confrontational, primarily in regards to the surveillance cameras themselves.

As described by Brown, a majority of the surveillance cameras in Manhattan are unmarked. This does not allow for the cameras to work as a deterrent, a response commonly suggested as being a benefit of the technology. Detourning the covert nature of most cameras, Brown stops for long periods of time as he discusses the technologies and related issues of crime prevention, public safety and individual rights, including readings from the Constitution of the United States. Stopping in the middle of crowded Manhattan sidewalks certainly is frustrating for those who wish to pass. The effect of a group of people, eyes trained on a virtually invisible technology, has a contagious effect: passers-by stop, look, and listen. Many join the tour. The once unmarked cameras are made known to a variety of people, becoming marked in the process.

The tours seem to shift the notion of performer as previously defined through SCP skits and plays. The tour can therefore be seen as detourning the notion of performer, and performance, allowing for a double meaning to be constructed. On the tour, I consciously acknowledge the presence of the camera, altering my behavior accordingly: nervously gawking at the camera, hiding my face, or flipping the bird. Through this performance, I temporarily deflect the gaze of the camera through my embodied practices.

\section{Embodied practices: doubling the panoptic gaze}

Bartky (1988) and Hyles (1999) have been critical of the bias towards a male subjectivity represented in Foucault's theory of the Panopticon. While Bartky provides specific examples of panopticism through self-monitoring habits such as dieting and applying cosmetics, Hayles focuses on the general disembodiment that results from Foucault's emphasis on the discursive construction of historical statements, in How We Became Posthuman (1999). Hayles analyses the development of Panoptic space in terms of its effects on the bodies of individuals within society.

Hayles is particularly critical of the way in which Foucault's theories ignore specific examples of the physical effects of Panoptic power: "Foucault's analysis . . diverts attention away from how actual bodies, in their cultural and physical specificities, impose, incorporate, and resist incorporation of the material practices he describes" (1999, p. 194). She is also critical of the Panoptic power of Foucault's writings: "Foucault thus participates in, as well as deconstructs, the Panoptic move of disembodiment" (1999, p. 194).

In an effort to further develop the theories behind panopticism - and to interject a particular notion of resistance as response - Hayles develops the idea of embodiment. She presents embodiment as a specific form of enunciation in contrast to the generalization that she interprets in Foucault's writings, drawing a comparison between 'the body' and embodiment. 'The body' is a social construct that is non-specific and normalized. Embodiment on the other hand, is "contextual, enmeshed within the specifics of place, time, physiology, and culture, which together 
compose enactment" (Hayles, 1999, p. 196). This emphasis on the specific responses that surveillance technologies elicit is crucial for an understanding of the critical potential for embodied critique in educational spaces.

The actions of Bill Brown - specifically the walking tours - represent instances of active embodiment. The normalized body, unaware of the gaze of the surveillance camera, acts according to numerous social cues. Walk. Don't Walk. Pass on the left. Avoid direct eye contact on the crowded SOHO sidewalk. Once Brown acknowledges the presence of the cameras, a shift occurs. Behavior is modified, and, briefly perhaps, represents a moment of embodied critique. The inscriptive power of surveillance technology - the power to control behavior - is temporarily shifted through the incorporated actions developed through the walking tour.

This is a shift that did not occur in the devil1.0 action. While I might perform an embodied action, the students in the classroom are passive viewers (a passivity referenced by the pseudointeractive aspects of the website). The issue of embodiment becomes relevant when they compare their positions in the classroom to the diagram on the website. They are made aware of the presence of the surveillance camera through my actions. They then have the option as to how they might modify their behavior when they pass the gaze of the camera, and more importantly, to compare the surveilled space of the union building with the classroom space.

The walking tours of Bill Brown and the SCP represent a form of panoptic pedagogy. Brown is not merely teaching the tour group about the technologies - he is opening up a space for dialogue within the surveilled public space. The possibilities for similar investigations in the classroom are present, if educators are willing to acknowledge the double meanings that are a product of pedagogy. Students consistently challenge the power structures that exist in school settings. As Apple and King (1990) suggest, the 'hidden curriculum' is reinforced when these potentially conflicting positions are ignored, or suppressed.

\section{Ittakesa village?}

The Hetzel Union Building became the center of controversy on the Penn State Campus in the spring of 2001. The "No Hate at Penn State Rally," organized by university administrators, became the site for a student protest, led by student leaders concerned with the way the university had dealt with recent racist death threats. After the administration, led by university president Graham Spanier, refused to meet with the concerned groups, a large group of students marched across campus to the HUB - Robeson Center, where many camped out for more than a week (Daily Collegian, Feb. 18, 2002). This protest, dubbed 'The Village,' led to the creation of the Plan to Enhance Diversity, and the Gye'Nyame Curriculum Committee which continues to discuss its implementation. Later in the same year, the administration installed Web cameras in select areas across campus - including the HUB - accompanied by a front page story titled "Eye Spy" in the Daily Collegian. 


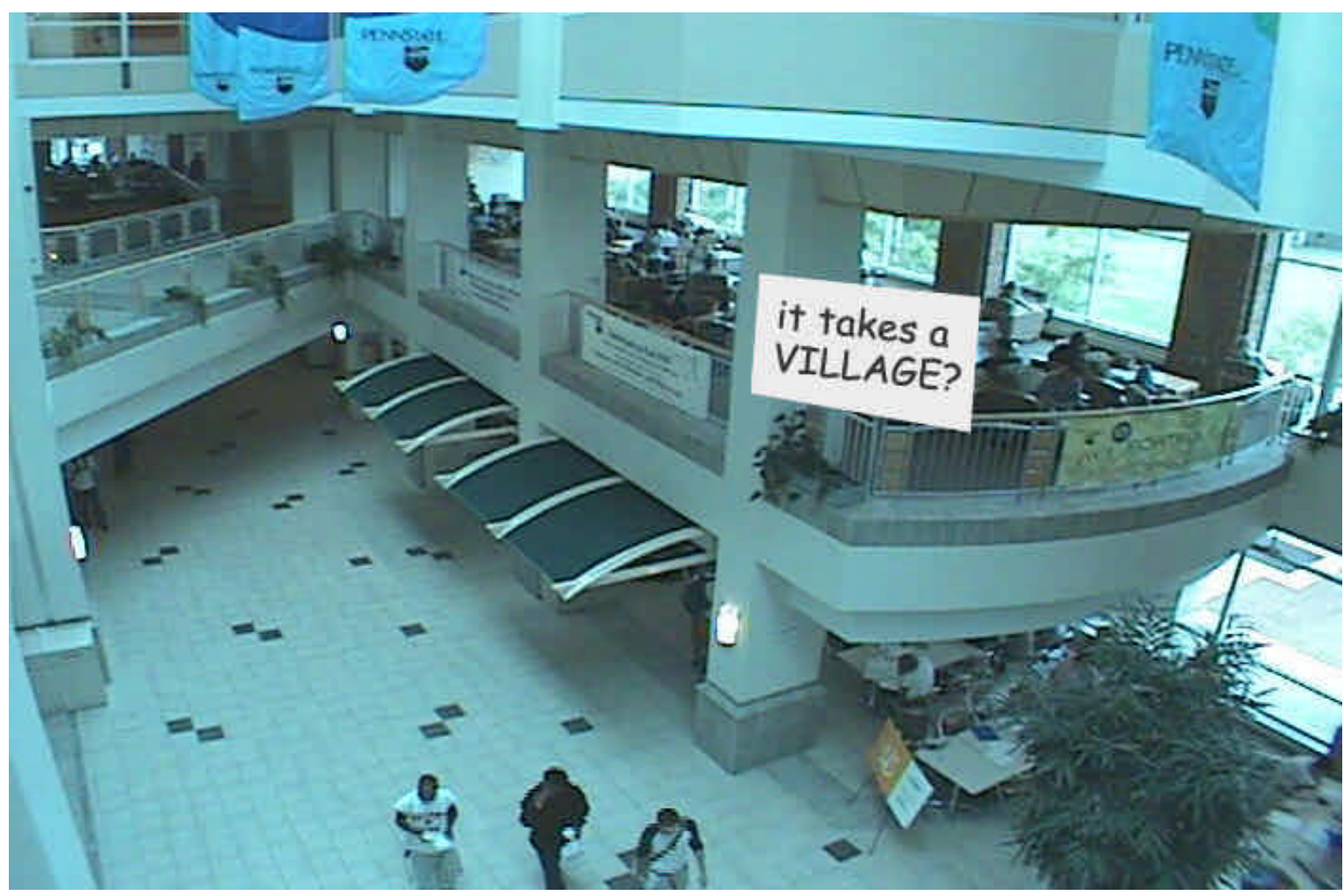

Figure 5: It takes a village?

While the web cams are promoted as a way for alumni to view areas of campus, including the renovated HUB, it seems peculiar that the single camera in the HUB be trained on one of the areas where 'The Village' was established. Operating from a central location, the webcam is similar in design to the central tower in the Panopticon. The major difference is the availability of 'real-time' images from the camera on the web, which allows anyone with Internet access the ability to watch from a decentralized position.

Fiske (1996) describes how technologies in general reinforce dominant power structures. Although developing technologies offer the potential for new forms of interaction, they frequently become another means for domination and control. In terms of the potential of surveillance technologies to reinforce racist ideologies, he writes: "Surveillance technology enhances the construction of whiteness as the space from which the other is viewed, and its development is so significant because it technologizes and thus extends a power application that is already widespread" (1996, p. 156).

It was this series of events that provoked me to plan devil1.0. While I was not involved in the original protests, I felt it was necessary to address its implications within the Art 100 classroom. I felt the need to engage the technology, not merely discuss it from a safe distance. Doing so made me question many issues: the legality of my actions, the ethics involved in such confrontations, my position as a white male graduate instructor at the university. We were able to discuss these issues in class, after dealing with the paradoxical aspects of the 'devil' website.

I had hoped that by actively engaging with the web cam that the students might see the possibility 
for embodied action on their part, and understand that this action was critical in nature, in keeping with the subject matter of the course and the recent student protests. It was also was important for this performance to take place during class time, when I could present an alternate form of instruction that was entirely informed by and framed through the technology that I wished to discuss.

The doubling represented by the detournement of the SCP has helped me to understand the potential for embodied critical acts within the classroom. Hayles focus on embodied practices is relevant to educational situations in which technologies are continually being introduced:

When changes in incorporating practices take place, they are often linked with new technologies that affect how people use their bodies and experience space and time. Formed by technology at the same time that it creates technology, embodiment mediates between technology and discourse by creating new experiential frameworks that serve as boundary markers for the creation of corresponding discursive systems.

(Hayles, 1999, p. 205)

The surveillance technologies that operate in the public spaces on the Pennsylvania State University campus have yet to create such discursive systems on a large scale. Within the Art 100 classroom, however, the dialogue that was created was helpful in posing possible responses to these technologies.

The actions related to devill.0 begin to address issues of embodiment and social control in educational spaces. Educators must explore the possibilities for embodiment in the classroom, as networked digital technologies increasingly normalize behavior. The visual arts classroom is a space where such critical responses can be constructed, where the theory underlying the gaze of surveillance technologies can be fused with aesthetic actions, where statements can be made to coexist and detournement can take place.

Hayles makes the point that embodied practices always accompany new technologies. If students are forming these critical responses in the visual arts classroom, how are they to be identified? Do they exist as subtle undercurrents, the power of which would be nullified if brought into the dominant pedagogical discourse? As I continue to recognize the possibilities for active embodied practices in my classroom, I also become more aware of student embodiment. I notice the subtlety of posture when interacting during group discussions. I acknowledge the importance of dialogue that exists outside of the normative constraints of the class, through email correspondence or Instant Messenger interactions. I look for opportunities to address these forms of communication as detournement, and to critique my role as active researcher in the classroom, to continue to reflect the panoptic gaze upon my own practice. 


\section{References}

Apple, M. W. and N. King (1990) Economics and control in everyday school life. In M.W. Apple (ed.), Ideology and Curriculum, 2nd edition. New York: Routledge, 43-60.

Barabási, A. (2002) Linked: the New Science of Networks. Cambridge, MA: Perseus Books.

Bartky, S. L. (1988) Foucault, femininity, and the modernization of patriarchical power. In I. Diamond and L. Quimby (eds.) Feminism and Foucault: Reflections on resistance. Boston, MA: Northeastern University Press, 210-223

Baumgaertel, T. (2001) Interview with Bill Brown (Surveillance Camera Players). http://www.rhizome.org

CNN (2003) School district installs cameras in every class, hall. 30 August. http://edition.cnn.com/2003/EDUCATION/08/12/classroom.cameras.ap/

Daily Collegian (2002) Village continues to work for diversity, 18 February, 1.

Debord, G. (1952) Theory of the derive. In K. Knabb (ed.) Situationist International Anthology, Berkeley, CA: Bureau of Public Secrets, 50-54.

Deleuze, G. (1988) Foucault. Minneapolis, MN: University of Minnesota Press.

Foucault, M. (1977) Discipline and Punish: the Birth of the Prison. (A. Sheridan, Trans.). New York: Random House. (Original work published 1975).

Fiske, J. (1996) Videotech. In N. Mirzoeff (ed.) The Visual Culture Reader. London: Routledge, 153-162.

Hayles, N. (1999) How We Became Posthuman: Virtual Bodies in Cybernetics, Literature, and Informatics. Chicago, IL: University of Chicago Press.

Rheingold, H. (2002) Smart Mobs: the Next Social Revolution. Cambridge, MA: Basic Books. 